\title{
Study on the Cultural Teaching in College English Education
}

\author{
H.M. ZHAO \\ Teaching and Research Institute of Foreign Languages, Bohai university, Jinzhou 121013, China
}

\begin{abstract}
Language is the carrier of culture and also is influenced deeply by culture and customs. Language learning should be carried out with culture learning. Currently, it is emphasized too much for learning of language knowledge while it is ignored for learning of the culture in college English teaching. This has seriously affected the English expression ability of college students and resulted in the failure of crosscultural communication. In this article, the author compares and analyzes the cultural differences between English and Chinese language, and puts forward the strategies of culture teaching of college English. The author hopes that it would be helpful to the college English education.
\end{abstract}

KEYWORD: Cultural differences; Contrastive analysis; thinking mode

\section{INTRODUCTION}

With the development of world economy and politics, the exchanges between nations and regions become more frequently. English has become the international language of communication. Currently, English education is highly valued for both primary education and higher education. A variety of teaching reform and teaching concepts have been put forward. However, the overall effect of English teaching is not satisfied. Although the students have learned English vocabulary and grammar, they cannot communicate with others easily and the purpose of communication has not been achieved. Some students even make the pragmatic errors of 'Chinglish', that is, the words are English while the expression is completely Chinese style. It is much common that pragmatic errors are often made in cross-cultural communication, and even cultural conflicts occur. The reason lies in that the domestic English teaching only attaches importance to learning of English language knowledge while ignoring the learning of English cultural knowledge. The students just learn English language knowledge while they do not acquire the corresponding cultural knowledge. They know little about the western moral values, etiquette, taboos and customs etc. This leads to the pragmatic errors in practical communication.

\section{RELATIONSHIPS BETWEEN LANGUAGE AND CULTURE}

According to the definition of $\mathrm{Hu}$ Wenzhong, culture is the product created by the people through long time efforts, and is the social heritage. Culture includes not only the beliefs, values, customs, and knowledge, but also the materials and apparatus. The concept of value is the core of culture. And the culture can be distinguished according to different values. Therefore, culture is the precipitation result in the process of development of human history and it determines the language expression and the thinking mode for people in the region. Due to the produce and development of language, the human culture can be inherited. So the culture influences on the language every hour and moment. Language is not only the carrier of culture but also the profile of culture [1]. The birth of language has its historical roots. When the cultural background and the language knowledge are separated in the process of language teaching, it will inevitably cause various errors of language application. When students learn the knowledge of English cultural background, such as Europe local customs and practices, religious customs, values and living habits, they can deeply understand the meaning of English, and this helps them to use English correctly. Therefore, language learning should be combined with the culture learning, which also promotes the learning of language. 
3 CONTRASTIVE ANALYSIS OF ENGLISH AND CHINESE CULTURE

Contrastive analysis is the branch of linguistics. It is the hypothesis based on the theories of constructivism and behaviorism psychology. It holds that foreign language learning is the transfer from habits of mother tongue language to habits of the foreign language [2]. When certain habits of mother tongue comply with the habits of foreign language, they promote the language learning, namely the occurrence of positive transfer. When the habits of mother tongue do not match the habits of foreign language, it is much difficult to learn the foreign language, namely the occurrence of negative transfer. Through the contrastive analysis between languages, the learners can foresee the possible difficulties and errors in foreign language learning. This is helpful to the foreign language learning. When the students carry out the contrastive analysis between the native language \& culture and the English language \& culture, they can foresee those difficulties in language learning, and this helps the students to overcome the difficulties caused by the great difference between cultural backgrounds. In 'Requirement of College English Curriculum', it is also clearly pointed out that college English curriculum is not only the basic course of language knowledge, but also the course to expand the knowledge and understand the world culture. Therefore, the teacher should combine the language teaching with culture teaching closely in class teaching and persists the culture teaching in the whole language teaching. In teaching, the teacher should perform the contrastive analysis and helps the students learn the background knowledge of English culture. In the following parts, the author will analyze the difference between English and Chinese cultures in detail.

(1) Difference of values. In Chinese traditional culture, the concepts of Confucianism have always been dominant. The Confucian concepts of 'doctrine of the mean' and 'Respect for people while being modest for yourself' have long been dominant. The extension of Confucian concepts constitutes the community culture of moral and value for Chinese. Chinese advocate courtesy and dislike pretentiousness and competition with others. Chinese hold that personal flaunt is disagreeable. In the aspect of value, Chinese advocate dedication and selfless help to others. Chinese think it is the unethical and selfish behavior that people put the individual interests above the interests of the group. Chinese people advocate the concept of 'deny self and return to propriety', that is, people overcome the individual desires and keep courtesy and etiquette. In China, the individual interest and individualism are derogatory, and they are the pronouns of selfishness. The western have been influenced by the spirit of humanism since the period of Renaissance. The humanism spirit believes that the world should be human-centered rather than god-centered. Therefore, the humanism spirit values the value and dignity of human and it believes that human is the creator in real life. It advocates that people should pursue happiness in real life by their own efforts. It also advocates the emancipation of individuality and individual rights. Under the influence of the spirit of humanism, the western generally respect individual rights and privacy. They do pursue the personal interests and advocate individualism. They believe that people can achieve their own happiness and wealth through personal effort. Few people are proud or shame of their own background of rich or poor family. Westerners focus on the competitive consciousness and self-awareness, and they also emphasize the individual independence and selfvalue. Children are instilled the independent consciousness and parents never interfere with the choices of their children.

(2) Difference of thinking mode. In the aspect of thinking mode, westerners emphasize logical thinking, while Chinese prefer the experience and intuition. Since the era of Aristotle in ancient Greek, westerners emphasize the ability of logical thinking and analysis. In modern times, Kant had fully explored the conditions of establishment and presence of science and metaphysics with the rational critical spirit. Hegel had argued the nature of the world can be known by rationality through dialectic thought. Under the influence of western philosophy, westerners think that logic and analysis are the only way to get the truth of nature. Therefore, westerners try to be objective in their speech and seldom join the affective factors of individual. Chinese have been influenced deeply by Confucianism. Confucianism often searches for and corroborates the proof of nature from the introverted thinking. They often think of the problem via the thinking mode of super-analysis and super-logic deduction, that is, words cannot express all one intends to say, and forgetting words as the meaning is caught. Therefore, Chinese value experience and intuition in the conversation, and they often add the personal feelings in the statement of things. Chinese emphasize the euphemistic and implicit expression, while westerners focus on the simple and direct expression. Influenced by the logical thinking, the reasoning and judging of 'one or the other' constitute the conversation and thinking of westerners. Westerners usually do not equivocate while Chinese advocate the subtle conversation with humility due to the rooted concepts of 'doctrine of the mean'. Chinese think that talking with others in straight-thinking mode is offensive and they advocate the implicit art of 'a bird is known by its note, and a man by his talk' [3].

(3) Difference of etiquette culture. Because of 
different values, western communicative language is much different from that of Chinese. For example, when two Chinese people meet, they often greet each other to say 'have you eaten?' If the Chinese greets the westerner by this way, the westerner will misunderstand that the Chinese invites him to dinner. Chinese often meet others to say 'where do you go?' For the westerner, however, this is a very impolite greeting. Westerners much care about their own privacy, therefore, they are much disgusted with those people who try to inquire or invade their privacy. Thus Chinese greeting is embarrassing and uncomfortable for the westerners. When meeting, Westerners usually greet others to say 'Hello', 'How do you do?' or 'Good day, isn't it?'. In Chinese etiquette culture, the old people are always respected. When greeting the old man, Chinese usually say 'Your old', 'old man', or 'old uncle' to him. When meeting the old people, Chinese usually help the old people actively, which shows their respect for the old people. While the westerners hate others to call them 'old people'. In western culture, 'old' means the person has the weak action ability and needs the help of others. It has the derogatory meaning. So it is very impolite to call an elder westerner old person. Similarly, in the west, it is not proper that one takes the initiative to help others. Westerners advocate the spirit of individual enterprise and hate others to interfere with their activities. Unless the westerners ask others for help, it is impolite help the westerners actively. Also, on the table, the hospitable Chinese master always says humbly 'I am sorry to cook only a few dishes for you', and this humble greeting even occurs with the table filled with plenty of dishes. The westerners would be rather puzzled because they think that there are enough dishes. Similarly, Chinese always persuade the guests to drink more wine and actively refill the bowel of guests. However, this behavior is impolite for the westerners since they think that the hosts force them to eat. Usually, the westerners just say 'Help yourself, please' to the guests.

(4) Difference of language habits. English and Chinese belong to different language families. English belongs to the Indo-European language family while Chinese belongs to Sino-Tibetan language family. English prefers the structure form. The connection in or between sentences usually takes the form of syntactic or lexical devices. In contrast, Chinese prefers parataxis, that is, the connection in or between sentences takes the form of semantic devices. For example, 'If I had known it would come to this, I would have acted differently.' In Chinese expression, the logical conjunction does not been used to connect two clauses in this sentences. However, their affiliation is implicit in logic. In English, the conjunction word 'if' is used to denote the affiliation of condition and results between two clauses. English prefers the static expression while Chinese prefers the expression with verb. English tends to use a noun or gerund to express the movement while Chinese often use the verb to do it. For example, in the sentence of ' $I$ am afraid of you misunderstanding me', a gerund is used to express the meaning of verb. English prefers the passive voice while Chinese prefers the active voice. The subjective of English is often an inanimate object, which can present the objective and accurate image to people. In contrast, the subjective of Chinese is often a person. For example, in the sentence of 'New actions must be taken to prevent the air pollution', a passive voice is used. If it is translated into Chinese, the subjective must be the people. Moreover, English prefers abstract meaning while Chinese prefers concrete meaning. This difference comes from the fact that the westerners prefer the logical thinking while Chinese prefer the holistic thinking. For example, in the sentence of "The absence of intelligence is an indication of satisfactory developments", abstract nouns of 'absence', 'intelligence', and 'indication' are used. When the sentence is translated into Chinese, these abstract nouns must be transformed into concrete verb and noun.

\section{STRATEGIES ON CULTURE TEACHING OF COLLEGE ENGLISH}

(1) Teacher should make full use of contrastive teaching mode in English teaching and performs the contrastive analysis on the characteristics of Chinese and English languages. Teacher emphasizes the difference of two languages, helps the students acquire the particularity of western culture, and analyzes the differences between two cultures. This can help the students use English accurately. In teaching practice, teachers should combine the content of text to perform the contrastive analysis on semantic culture. Teacher not only explains the meaning of words to students, but also contrastively analyzes the cultural connotation of words. The difference between the connotative and extensive meaning of words should be emphasized and this makes the students grasp the vocabulary accurately. In the habits of English expression, teacher should stress the structural arrangement of English articles and idiomatic usage of words and sentences as well as the basic structure of language. This makes a sharp contrast to Chinese and therefore facilitates the students to master the expression habits of English. Moreover, the teacher should make full use of the advantage of Internet, and refers the extracurricular reading materials with typical significance to the students, so as to extend the students' understanding on European and American cultures and to strengthen the input of English culture knowledge[4].

(2) Teacher should combine the culture teaching 
with the language teaching by appropriate teaching methods. Teacher should consciously combine with language teaching to introduce the social and cultural knowledge of western countries to the students and enhance their sensitivity to cultural differences between English and Chinese. Teacher should consciously show the similarities and differences between two cultures and make the students acquire the ability of contrastive analysis. At the same time, teacher should introduce timely the background knowledge of English culture, customs, and communication rules to the students, and guide the students to use the appropriate language in different contexts of language, and extend the knowledge structure according to the existing knowledge of students. In addition, teacher should collect the materials of English culture and design the multimedia courseware. Teacher shows vividly the knowledge of European and American cultures to the students via multimedia, slides and videos. This can make the students acquire the knowledge of customs and language patterns. Teacher asks the students to simulate the dialogue in certain scene and makes them experience the exotic culture atmosphere. The teacher should be familiar with the various methods of cultural introduction and improve the practical operating ability of language teaching. According to the students' language ability of acceptance and cognition, the teacher adopts flexible and appropriate teaching methods to cultivate the cross-cultural communicative ability of students in different learning states[5].

(3) The teacher should guide the students to enhance the cultural knowledge and communicative ability. The content of culture is extensive and complex while the teacher can introduce only a small portion of it to the students. Therefore, the teacher should encourage the students to read a large number of extracurricular reading materials in order to accumulate the cultural knowledge of students. The class should be student-centered. Teachers should change their teaching concepts and stimulate and cultivate the ability and consciousness of culture contrastive analysis. This can help them use English correctly and achieve the purpose of communication. Teacher should encourage and guide the students to contact the original English publications, films and works. This helps the students experience the difference between English hand Chinese cultures. Teachers should refer some newspapers, magazines on English cultures to the students and promote the ability of English learning and culture appreciation. Moreover, teachers can guide the students to use the Internet to get more information of certain culture.

\section{CONCLUSIONS}

As the whole, culture and language can not be separated from each other. The learning of foreign language should be performed simultaneously with the cultural learning. Currently, too much has been emphasized on learning of language knowledge while little is stressed on the cultural learning in teaching of college English. This generally causes the pragmatic failures in cross-cultural communication and hinders the communication. Therefore, culture learning should be integrated into the language teaching category, and this can make the students to use English more accurately and improve the efficiency of language learning.

\section{REFERENCES}

[1] Hall, E.T., 1959, The Silent Language, Anchor Books

[2] James, C. 1980, Contrastive Analysis, Longman Group UK Limited.

[3] Kim, Youngyun, Gudykunst, William, B., 1988, Theories in Intercultural Communication, Sage Publications.

[4] Levine, D.R., Baxter, J. McNulty, P., 1987, the Culture Puzzle: Cross-Cultural Communication for English as a Second Language, Prentice-Hall, Inc.

[5] Valdes, J.M., 1986, Culture Bound: Bridging the Cultural Gap in Language Teaching, Cambridge University Press. 